\title{
Reflexiones de docentes noveles y en formación sobre la inclusión educativa: un estudio cualitativo
}

\author{
Katherine Gajardo. Universidad de Valladolid \\ Recepción: 03.03.2019 | Aceptado: 15.10.2019 \\ Correspondencia a través de ORCID: Katherine Gajardo \\ iD 0000-0001-9972-6116 \\ Citar: Gajardo, K (2019). Reflexiones de docentes noveles y en formación sobre la inclusión educativa: un \\ estudio cualitativo. ReiDoCrea, 8, 167-185.
}

Resumen: Los procesos de inclusión en educación representan un tópico interesante para la investigación actual. Algunos estudios relevantes han demostrado que las representaciones sociales, concepciones y/o actitudes de las y los educadores sobre la inclusión se consideran como barreras para la misma (Echeita, 2008), por lo que se hace necesario identificar puntos de acción y ofrecer remediales formativas coherentes. El presente estudio tiene por objetivo analizar el discurso reflexivo sobre inclusión educativa de seis docentes y estudiantes de Magisterio que han recibido formación en programas similares, identificar significados que asignan al concepto y exponer cómo llevan su discurso a la práctica. El estudio, de características cualitativas, fue desarrollado mediante entrevistas en profundidad semiestructuradas y utilizó como referencia los modelos de Garnique (2012) y López, Echeita y Martín (2010) para identificar representaciones sociales, concepciones y actitudes sobre inclusión educativa. Los resultados indicaron que las y los participantes presentan en su discurso un perfil inclusivo, mas algunos de los significados otorgados al concepto siguen portando etiquetas de colectivos marginados. La investigación permite concluir que la reflexión pedagógica de los participantes se caracteriza por un tono social y axiológico, y que, discursivamente, proponen acciones pedagógicas coherentes con el modelo inclusivo.

Palabras clave: Actitudes del docente | Educación Universal

\section{Thoughts of new and trainee teachers on inclusive education: a qualitative study}

\begin{abstract}
Inclusive education processes have been a topic of interest in the ongoing research. Some relevant studies have shown that social perceptions, notions and/or attitudes of educators on inclusion are considered barriers themselves against the cause (Echeita, 2008), that is why points of action must be identified and coherent formative remediations offered. This study aims to analyze the thoughtful speech of six teachers and trainee teachers on inclusive education who received training under similar curricula, identifying what meanings they assign to the concept itself and explain the way they put their discourse into practice. This study, of qualitative nature, was developed through semi-structured in-depth interviews and the models of Garnique (2012) and López, Echeita, and Martín (2010) served as a reference to identify social perceptions, notions and/or attitudes of educators on inclusive education. The results suggested that participants show an inclusive profile in their discourse, but some of the meanings attached to the concept itself are still related to the stigmatization of marginalized groups. The research provides a ground for the conclusion that pedagogical reflection of the participants is characterized by a social and axiological tone and that, discursively, they propose pedagogical actions that are consistent with the inclusive model.
\end{abstract}

Keywords: Teacher Mindset | Universal Education

\section{Introducción}

La acción reflexiva de las y los docentes respecto a su labor se ha considerado como un elemento imprescindible para el desarrollo de aulas inclusivas (Ainscow, 2005; Arnaiz, 2003; Cardona, 2006). Los discursos favorables respecto a la diversidad, que se alejan de propuestas basadas en estereotipos y etiquetas sociales, muchas veces eliminan barreras importantes al momento de educar a ciudadanos de un mundo que se caracteriza por su heterogeneidad.

La educación formal, a lo largo de las últimas décadas y por medio de diversas acciones sociales, políticas y culturales, ha ido adaptando su enfoque tradicional, caracterizado por la mera transmisión de conocimientos, a un enfoque más activo y crítico, el cual 
supone una escuela que trabaja para el bien común en una sociedad diversa (López, 1999; Klinger, Mejía y Posada, 2013). En este nuevo enfoque, la acción de las personas que realizan docencia se caracteriza por realizar análisis profundos sobre su acción, transformándose en investigadores activos de su contexto (Stenhouse, 1984), con lo cual deben generar procesos de mejora constante en torno a su labor, la cual consiste no solo en lograr que sus estudiantes adquieran saberes y desarrollen competencias relacionadas con estos, sino que los guíe al desarrollo de posturas críticas.

El reto de avanzar hacia una pedagogía activa y crítica, con maestras y maestros conscientes de su labor social y a estudiantes incluidos en un sistema heterogéneo, ha llevado a la escuela, a concebir nuevas opciones, sobre todo en cuestiones de acceso, participación y rendimiento. En este contexto, la educación deja de ser el bien de unos pocos y se democratiza. Los habitantes del mundo se hacen conscientes del rol de escuela como elemento clave para la superación de las desigualdades, después de todo se comienza a instituir la realidad de que todas las personas poseen, en esencia, los mismos derechos.

Casi tres décadas se han cumplido ya desde la primera "Conferencia sobre educación para todos", en la cual se confirmó la premisa de que todas las personas, independientemente de su origen socioeconómico y cultural y de sus capacidades individuales, innatas o adquiridas, tuvieran las mismas oportunidades de aprendizaje en cualquier contexto educativo (UNESCO, 1990). Se asimiló el concepto de diversidad humana, el cual requiere de una respuesta educativa individualizada y comprensiva por parte de las instituciones educativas, las cuales se han imbuido de esta misión para forjar una sociedad más justa para todos.

En este contexto se expone la investigación desarrollada en esta propuesta, la cual posee por finalidad observar cómo los nuevos maestros y maestras, y estudiantes de Magisterio, representados por un grupo en particular, son conscientes del cambio de paradigma educativo, y cómo ellos y ellas observan y significan su profesión desde el punto de vista reflexivo en pos del logro de los fines de la educación inclusiva.

La relevancia que posee este estudio es generar conciencia sobre la importancia que posee el discurso reflexivo docente al iniciar y concluir la formación en Magisterio y en etapas iniciales del ejercicio de la profesión docente. Desde hace unos años se ha generado una conciencia investigativa sobre el valor que poseen las actitudes del profesorado en los fenómenos de inclusión educativa (Sánchez, Díaz, Sanhueza y Friz, 2008; Granada, Pomés y Sanhueza; 2013) y las concepciones de las y los docentes a la hora de potenciar posturas concordantes con el modelo inclusivo en educación formal (Garnique, 2012), mas, gran parte de los estudios no profundizan sobre el discurso propio y personal de cada maestro a la hora de hablar de inclusión, lo que omite el valor personal e individual del concepto. Por otro lado, las investigaciones generalmente se centran en profesionales de la educación con gran experiencia o estudiantes que no han tenido acceso a información relacionada a la justicia social y la inclusión educativa, además de servirse única y exclusivamente de cuestionarios cerrados en investigaciones cuantitativas que no analizan expresiones más profundas.

La importancia de la investigación aquí desarrollada está en dar a conocer el valor que posee el discurso de cada maestra y maestro, además de sus creencias personales para lograr una anhelada equidad y justicia social. Generar experiencias que potencien el discurso reflexivo en todos los momentos formativos que atraviesen las personas que eligieron el camino de la docencia es una necesidad antes y durante el ejercicio de la profesión, más aún en este último punto, pues cada vez se añaden más cargas administrativas a las y los educadores, lo que deja menos tiempo para dedicar su acción 
a la mejora continua y el fomento de espacios de diálogo colaborativo entre colegas, lo que se contradice con aquellos principios que poseen algunas de las propuestas de la inclusión educativa más aceptadas por nuestra sociedad (Ainscow, 2001).

\section{Objetivos de la investigación}

El objetivo general que posee este estudio es describir cómo personas representantes de una nueva generación de docentes, tanto estudiantes de Magisterio como maestros noveles, realizan la reflexión pedagógica en torno al tema de la inclusión educativa, qué tipo de significados simbólicos y semánticos asignan a esta acción y cómo llevan el discurso a la práctica para inclusión de la diversidad en educación.

\section{Método de investigación}

El método desarrollado en esta investigación de tipo cualitativo se centró en el análisis del discurso reflexivo pedagógico de maestros y maestras noveles y estudiantes en formación de Magisterio mediante entrevistas, las cuales se concentraron en caracterizar sus concepciones, actitudes y representaciones sociales sobre la inclusión educativa, todo lo anterior sobre la base de dos modelos teóricos generados por López, Echeita y Martín (2010) y Garnique (2012).

El análisis discursivo se situó desde una perspectiva interpretativa (Krause,1995), lo cual supone un estudio de la realidad construida a través de los significados que otorgan los sujetos a las experiencias que viven; de este modo la investigación realizada sirve para describir como las personas le asignan significado a las cosas que experimentan. Este tipo de investigaciones da especial importancia a la subjetividad de la conciencia humana, por lo cual no busca la generalización y su valor subyace en el análisis de la perspectiva de realidad que cada ser humano posee en su individualidad.

\section{Instrumento}

La tipología de entrevista que se utilizó en este estudio es la que Wengraf (2001) identifica como "entrevista en profundidad". Las entrevistas en profundidad son conversaciones profesionales, con un propósito y un diseño orientados a la investigación social, que exige del entrevistador gran preparación, habilidad conversacional y capacidad analítica (p.4).

Las entrevistas en profundidad van más allá del registro de discursos, los cuales jamás son absolutos, sino que constituyen un marco social de la situación de la entrevista. La conversación nace de una pregunta previamente determinada por el entrevistador, la cual da espacio a una situación dialógica, así, tanto el entrevistador como el entrevistado construyen y reconstruyen al instante ese discurso respecto a la situación, tiempo y espacio en el que están (Alonso, 1994).

En cuanto al diseño de las entrevistas de este estudio, se apeló al criterio de estandarización y estructuración (Vallés, 2000), particularmente el de la "entrevista estandarizada no programada". La elección de esto modelo fue porque presenta términos familiares a todos los entrevistados, además no se obliga a la utilización de una secuencia predefinida por lo que se presentan las preguntas de forma contextual en la medida que va naciendo la conversación. Esto quiere decir que, aunque se generó un guion para la entrevista, la entrevistadora no estaba obligada a seguir un patrón determinado, lo que dio a los entrevistados libertad de expresión. 
La utilización en este estudio de la entrevista en profundidad estandarizada y no programada como método de recolección de datos, se debe al valor semántico que supone al interactuar discursivamente con un sujeto, el cual se identifica como portavoz de un grupo social determinado (maestro novel, estudiante en prácticas o estudiante de primer curso) que, a partir de su reflexión, es capaz de analizar y modificar su alrededor en cuanto al tópico tratado: la inclusión educativa.

\section{Diseño del instrumento}

Las entrevistas siguieron las pautas de dos propuestas validadas en otros contextos investigativos, por lo cual fueron adaptadas a la situación y propuesta teórica de la investigación realizada el año 2017. En primer lugar, está el modelo de Garnique (2012) y en segundo lugar el diseño de López, Echeita y Martín (2010).

La investigadora mexicana Felicita Garnique (2012) desarrolló un guion de entrevista que contiene preguntas de asociación y que posee la finalidad de obtener evocaciones espontáneas y selección de elementos significativos sobre la inclusión educativa en la reflexión docente. La autora, luego de analizar su contexto, generó preguntas que identifican representaciones sociales de docentes en ejercicio, señalan modos discursivos respecto a la inclusión y ponen de manifiesto la implicación del locutor y los juicios que sustentan su argumentación.

El diseño de López, Echeita y Martín (2010) corresponde a un "cuestionario de dilemas", en el cual se exponen situaciones referidas a alumnado con diferentes problemas escolares, así como situaciones hipotéticas sobre el trabajo colaborativo docente, las formas de agrupamiento de estudiantes y valoraciones sobre la educación inclusiva. En este cuestionario, las y los maestros siempre se enfrentan a situaciones hipotéticas y deben seleccionar una de tres opciones dilemáticas que incluyen muchas veces pensamientos que suelen no decirse públicamente.

El guion de la entrevista que se adaptó para la investigación respondió a una conjunción adaptada de las propuestas, por ello en su diseño y posterior aplicación se ejecutó en dos partes, una primera, en donde los entrevistados se identificaban y generaban un breve relato sobre su vida y elecciones profesionales, y además, respondían a preguntas relacionadas a su contexto en cuanto a la propuesta de Garnique (2012), y una segunda, en donde se les presentaban algunas de las situaciones hipotéticas generadas por López, Echeita y Martín (2010) y se les pedía opinar y ofrecer remediales a dichas situaciones.

La adaptación de gran parte de las preguntas se fundamentó en que parte de los participantes de la investigación no eran docentes en ejercicio - eran maestros y maestras en formación -, por lo cual algunas situaciones no concordaban con experiencias personales. El guion finalmente elaborado se sometió a revisión de dos docentes universitarios, especialistas en materias relacionadas con la educación inclusiva y la atención a la diversidad, así como a otro docente que imparte seminarios de doctorado sobre la entrevista como estrategia de investigación cualitativa. Los cambios sugeridos por estos expertos se refirieron a dos de las situaciones dilemáticas y a la expresión sintáctica de dos de las preguntas. Esas propuestas de modificación se tuvieron en cuenta en la redacción del instrumento utilizado.

La entrevista (ver anexo) poseyó dos diseños, uno que atendía a los entrevistados estudiantes de Magisterio, de 14 preguntas abiertas y 8 situaciones dilemáticas, y otro, que respondía a los maestros noveles, de 18 preguntas abiertas y 8 situaciones dilemáticas. 


\section{Participantes}

Las y los participantes del estudio fueron seis personas que estudiaban o estudiaron en el Campus María Zambrano de la Universidad de Valladolid el Grado en Educación Primaria o Infantil y que respondían a las siguientes características:

1. Entrevistados nivel 1: Una estudiante y un estudiante de primer curso del Grado en Educación Primaria o Infantil, seleccionados por disposición personal bajo criterio de conveniencia.

2. Entrevistados nivel 2: Una estudiante y un estudiante de cuarto curso del Grado de Educación Primaria o Infantil, seleccionados por disposición personal bajo criterio de conveniencia.

3. Entrevistados nivel 3: Una docente y un docente ejerciendo el primer año de la profesión, seleccionados por disposición personal bajo criterio de conveniencia.

Las entrevistas tuvieron una duración media de 57 minutos y se desarrollaron en el campus María Zambrano de la Universidad de Valladolid (Segovia, España). Se registró la información obtenida con una grabadora y en un diario de campo. Para el análisis se transcribieron las entrevistas, lo cual se llevó al programa Atlas Ti. para un posterior análisis sobre la base de la bibliografía escogida.

\section{Análisis de los datos}

El análisis de los datos se respaldó en las propuestas de Garnique (2012) y López, Echeita y Martín (2010) para identificar concepciones, actitudes y representaciones sociales sobre inclusión educativa. Además, siguió un plan de análisis independiente de las investigaciones fuente, que se concretó en este plan de acciones:

a. Grabación y edición del audio de las entrevistas.

b. Transcripción de las entrevistas y las anotaciones del diario de campo a un documento de texto.

c. Depuración de datos.

d. Codificación de datos y organización de la información mediante el uso del programa Atlas Ti.

Las categorías desarrolladas para el análisis de las entrevistas se organizaron en tres grandes familias: Representaciones sociales sobre inclusión educativa, Concepciones sobre inclusión educativa y Actitudes hacia la inclusión. Asimismo, dichas categorías se subdividieron en etiquetas específicas, que fueron determinadas por las bases teóricas que proponen los autores de referencia:

Tabla 1. Categorías para el análisis, códigos y bases teóricas 

sobre inclusión educativa (Garnique 2012)
Representaciones sociales

Evocación del concepto inclusión.

Palabras de evocación. Significación del concepto inclusión de la diversidad. Problemáticas con las que identifica la inclusión. Valores declarados.

Formación sobre inclusión. Formación temprana. Conocimientos del currículum.

\section{Concepciones sobre} inclusión educativa (López, Echeita y Martín, 2010)
Subdimensión 1

Subdimensión 1 (p.2)

Subdimensión 2

Subdimensión 3

Subdimensión 4

Subdimensión 6

Subdimensión 7
Representación social de inclusión (Moscovici, 1997). Campo de la información sobre inclusión (Moscovici, 1997).

\author{
Naturaleza de las \\ diferencias (Coll y Miras, \\ 2001). \\ Responsabilidad de los \\ apoyos (Echeita, 2006; \\ UNESCO, 1990). \\ Adaptación de los objetivos \\ (Coll y Miras, 2001). \\ Nivel de Equidad (Marchesi \\ y Martín, 1998). \\ Valores declarados \\ (Escudero, 2006; \\ (Etxebarría, 2003). \\ Ideología educativa \\ (Marchesi y Martín, 1998).
}

Campo de las actitudes sobre inclusión (Moscovici, 1997).

Actitud hacia la mejora escolar (Ainscow,

Beresford, Harris, Hopkins y West, 1994).

\section{Resultados}

A partir de la reflexión pedagógica y dialógica generada en el contexto de las entrevistas, se logró obtener recursos clave para la identificación de las representaciones sociales, concepciones y actitudes de los participantes sobre la inclusión educativa, e identificar elementos teóricos clave en los procesos formativos de quienes representan una nueva generación de maestros formados conceptualmente respecto a la inclusión educativa.

\section{Representaciones sociales sobre educación inclusiva en el discurso pedagógico}

Representaciones sociales sobre inclusión en el aula se identificaron por medio de dos tipos de preguntas, unas llamadas "de evocación", en las cuales las y los participantes recordaban experiencias relacionadas a aspectos previamente delimitados, y otras "de 
opinión", en las cuales las y los entrevistados respondían de acuerdo con su reflexión personal.

Para analizar las respuestas a las preguntas de evocación, el método se sustentó en un procedimiento de recorte de campos de referencia en el discurso, en el cual se identificaban campos semánticos. Las respuestas a las preguntas de opinión se analizaron de acuerdo a la actitud cognitiva del discurso, que pueden ser de tipo "constativo", cuando la persona se presenta como testigo de un hecho; "proyectivo", cuando la persona se anticipa o predice un hecho; "axiológico", cuando la persona emite un juicio de valor; "prescriptivo", cuando la persona ofrece formas de acción o "metadiscursivo", cuando el sujeto habla de su propio discurso (Garnique, 2012).

\section{Campo de la representación social en sí misma}

El campo de representación social sobre inclusión educativa se analizó en aquellas preguntas que pedían al participante una evocación de conceptos relacionados con la inclusión educativa. Siguiendo el modelo de Garnique (2012) las palabras mencionadas se identificaron en tres campos: "educativo", "social" y "axiológico" de la siguiente manera:

Tabla 2. Palabras relacionadas con la expresión "diversidad escolar" más utilizadas por los participantes

\begin{tabular}{ccc}
\hline Educativo & Social & Axiológico \\
\hline Lenguaje & Inclusión social & Sentimiento de \\
Cultura & Problema social & superioridad \\
Acompañamiento del & Diversidad & Ayuda/ ayudar \\
tutor & Identidad & Miedo \\
Trabajo interdisciplinar & Género & Dogma \\
Barreras curriculares & Exclusión social & Diferencias \\
& Falta de diálogo & Aceptación \\
& Marginación & Fortaleza \\
& & Pacifismo \\
& & Tolerancia
\end{tabular}

Los conceptos se situaron principalmente en el campo axiológico, seguido del social y finalmente del educativo. Los entrevistados del nivel 1 (estudiantes de primer año) se orientaron más al ámbito social, los entrevistados del nivel 2 (estudiantes de último año) centraron su discurso en el ámbito social y axiológico y finalmente, los entrevistados del nivel 3 (maestros noveles) presentaron un discurso orientado casi en su totalidad al plano axiológico (integrando también fuertes elementos sociales y educativos):

(...) se dice que es inclusiva porque no tenemos que dejar a nadie fuera, y entonces la educación tiene que procurar, igual que todos los gobiernos, y todas las cosas tiene que estar al cuidado de todos y, como he dicho antes, la educación me parece la base de la sociedad y de los cambios sociales (Entrevistada nivel 1).

Nunca he pensado la otra opción (distinta a la inclusión). Empezando porque nadie es igual que otra persona; es imposible que no exista diversidad en un aula, no se puede pretender que todos los alumnos estén cortados por el mismo patrón porque todos tienen padres distintos, características distintas, viven en sitios diferentes (...) La inclusión es un derecho que se tiene que dar en cualquier centro de educación (Entrevistada nivel 2). 
(...) creo que dicen que debe ser inclusiva, básicamente porque chocaría mucho una propuesta de segregar a los alumnos según sus diferencias. Entonces la tendencia, estoy seguro, la tendencia de los maestros que viven el día a día en las escuelas es crear alumnos, y centros, y espacios, cada vez más inclusivos (Entrevistado nivel 3).

En cuanto a los elementos mencionados por la evocación conceptual de la "inclusión" las y los participantes en su totalidad describieron situaciones vitales:

Entrevistados de nivel 1: La entrevistada recordó una experiencia educativa que había tenido en África y cómo desde un punto de vista docente, intentó propiciar elementos inclusivos en un sistema tradicional. El entrevistado recordó cuando estaba en la escuela y observaba un exceso de estereotipos, exaltando la marginación a los estudiantes de origen gitano.

Entrevistados de nivel 2: Ambos entrevistados recordaron episodios relacionados con su propia educación y sus experiencias en grupos de diversificación, en este enfoque, establecen una crítica a los procesos de integración que suponen la marginación total o parcial de estudiantes con dificultades.

Entrevistados de nivel 3: Ambos entrevistados expusieron experiencias similares con estudiantes diagnosticados con Trastorno del Espectro Autista, definiendo las acciones que realizaban en sus centros para afrontar la educación de las personas con Autismo y Asperger.

El discurso predominante en todas las reflexiones fue el de definir la inclusión desde una imagen generalizada de la diferencia: las evocaciones tienen por principales protagonistas a personas de colectivos marginados.

Cuando se les solicitó a las y los entrevistados que dieran una significación del concepto de inclusión de la diversidad, las respuestas siempre se orientaron a describir una idea del derecho humano a desenvolverse en una sociedad diversa:

Si damos cabida a la educación a personas distintas, con distintas visiones, distintas historias de vida, distintos sentimientos, distintas formas de actuar, al fin y al cabo, vamos a tener más soluciones posibles. Con lo cual no creo que la inclusión sea solo buena para los niños que se incluyen, sino que es bueno, para la sociedad en general (Entrevistado nivel 2).

Dentro de esta línea solo una participante realizó una reflexión orientada a la labor de los y las maestras en cuestiones de inclusión educativa:

En la escuela, por ejemplo, en el ámbito educativo tienes que, como docente, incluir y tratar de llegar a todo el alumnado, a todas las personas, por eso yo creo que es inclusiva, porque tiene que incluir a todos y cada uno de tus alumnos y de tus alumnas (Entrevistada nivel 3).

Otro de los elementos que conforman el imaginario de los participantes del estudio en cuanto a la inclusión de la diversidad en las aulas es el que identifica las problemáticas que enfrenta la inclusión educativa. Los modos que dominaron el discurso fueron en su mayoría contrastivos, o sea, los entrevistados otorgaron múltiples ejemplos de problemáticas de inclusión en las aulas, ya sea a partir tanto de experiencias como de saberes. El segundo modo discursivo que destaca es el axiológico, es decir la descripción de juicios de valor sobre cómo se trabaja hoy la inclusión en las aulas. En 
cuanto al modo discursivo prescriptivo, o sea el que indica acciones a seguir, se puede afirmar que existió minoritariamente en el discurso de la maestra novel participante:

Me parece importante, el leer y el conocer (...) pero también la práctica, el intentar... el ensayo-error, el intentar poner en práctica lo que han hecho otros compañeros o en ver ciertas experiencias para incluirles a todos (Entrevistada nivel 3).

El elemento final del enfoque de la representación social sobre inclusión es aquella que refiere al estereotipo de docente inclusivo que significan las personas colaboradoras del estudio. En este ámbito, al aunar los discursos se obtuvieron las siguientes características:

Tabla 3. Características del modelo de docente inclusivo

\begin{tabular}{c}
\hline Una maestra o un maestro inclusivo debe: \\
\hline - Tener compromiso con la mejora educativa. \\
- Tener flexibilidad y apertura al cambio. \\
- Poseer consciencia de las necesidades de sus estudiantes. \\
- Poseer gusto por el estudio y el saber. \\
- Poseer un repertorio de variadas metodologías para animar a \\
sus estudiantes. \\
- Tener creatividad y empeño. \\
- Poseer empatía. \\
- Poseer independencia. \\
- Demostrar cariño. \\
- Tener sentido del humor.
\end{tabular}

\section{Campo de acceso a la información}

En el campo de la información, que se obtuvo de respuestas a preguntas sobre formación y disposición a aprender de forma personal sobre inclusión educativa, existieron evocaciones orientadas a la formación universitaria:

Las clases de los profesores en "Educación para la Paz y la lgualdad" "Organización y Planificación escolar" así un poco los dos, puesto, vamos, ciertas cosas, siempre viene muy bien para concienciarte y saber un poco (Entrevistado nivel 1).

Parte las asignaturas que trataban de la inclusión, había la dimensión "Educación para la Paz" que empezaron con el tema de la inclusión. Luego, en segundo tuvimos "Intervención educativa" (...) también se centraba mucho en inclusión. Y luego en el "Practicum", para hacer el diario y tal y la realidad del aula, pues también, hay que formarse (Entrevistada nivel 2).

Resulta interesante señalar como, a pesar de las diferentes asignaturas que habían cursado, los entrevistados del nivel 2 y nivel 3 aún poseían recuerdos intactos sobre su proceso de formación en la asignatura "Educación para la Paz y la Igualdad".

En cuanto a acceso a la información independiente de formación universitaria, solo una entrevistada aun en formación (nivel 1) indicó haber tomado cursos de especialización o haber asistido a seminarios anexos a la educación formal. En esta misma línea, tanto la maestra como el maestro novel habían proseguido estudios de Postgrado luego de 
terminar el Grado en Educación Primaria, y en dichas experiencias formativas obtuvieron lo que definen como "pinceladas" sobre inclusión educativa y social:

Conocí mucho sobre ciertas cosas, trastorno por déficit de atención, eh, todos esos temas, conoces y es normal, te tienes que formar en torno a esos temas (...) en esa misma asignatura se podría dar un enfoque sobre prácticas inclusivas, ahora que estamos hablando de ello (...) además el máster, que tiene, bueno, un poquito. Una pincelada sobre educación inclusiva (Entrevistado nivel 3).

Hice el Máster en Cooperación, antes, cuando acabé la carrera. Pues ya te digo, un poco por la trayectoria social y cooperación que he tenido (...) y entonces me vinculé a una ONG aquí en Segovia con la que nos fuimos allí (...) todo ha estado más relacionado a la cooperación (...) intento... que ese sea día a día mi estilo. Me queda mucho por formarme, pero intento que sea ese el estilo, la cooperación (Entrevistada nivel 3).

En cuanto a la responsabilidad de formación, solo una participante expresó que personalmente sentía que debía motivarse a leer y aprender un poco más sobre tema, para obtener fuentes directas (autocrítica formativa):

Yo recuerdo que sí que tuvimos, eh, ciertas actividades y asignaturas de inclusión (...) no tengo ningún autor, ni ninguna referencia bibliográfica a la que yo pueda... no recuerdo ¡vamos! entonces es una tarea pendiente por mi parte porque yo debo, eh, tener ciertos conocimientos y bases para poder tratar este tema (Entrevistado nivel 3).

Finalmente, en lo que respecta al conocimiento curricular, las personas entrevistadas señalaron poseer conocimientos sobre el currículum vigente y tenían algunas nociones sobre las leyes de inclusión en educación, pero su opinión variaba en cuanto a la utilidad de la política pública en educación.

\section{Campo de Identificación con la inclusión educativa}

En el campo de la identificación axiológica con el fenómeno de la inclusión educativa, los maestros entrevistados poseen una posición concordante: en la ley está presente el eje de la atención a la diversidad y se pide aplicarla, pero las formas en las cuales se lleva a cabo muchas veces pueden ser erróneas, por las subjetividades políticas. Los entrevistados de nivel 2 enfatizaron que el currículum ofrecía lineamientos orientados a la diversidad, pero con un énfasis en la no colaboración, dicho aspecto se veía en el fenómeno de la segregación por categorización en las escuelas o la importancia que poseen los resultados de las pruebas estandarizadas.

\section{Actitudes sobre inclusión educativa}

Las representaciones sociales corresponden a una "red de conceptos e imágenes interactuantes cuyos contenidos evolucionan continuamente a través del tiempo y el espacio" (Moscovici, 1987. p. 220). Desde esta teoría resulta imprescindible describir cómo se produce la interacción conceptual entre la teoría y la práctica, por ello y con la finalidad de profundizar el aspecto de la acción pedagógica-discursiva se indagó sobre las actitudes de los participantes del estudio en cuanto a la educación inclusiva.

El primer análisis correspondió a cómo actúan las y los entrevistados ante los problemas educativos y qué acciones proponen para superarlos. Para lograr este objetivo se invitó a desarrollar una lista de valores relacionados con el concepto del estudio, para así identificar campos semánticos del orden axiológico:

Tabla 4. Valores declarados y frecuencia de mención en la pregunta ¿qué valores fomenta la inclusión educativa? 


\section{Valores}

Cooperación (5) Empatía (5) Respeto (4) Tolerancia (4) Autoestima (3) Esfuerzo (3)

Los valores mayoritariamente mencionados están relacionados con el aspecto social, en este eje los valores más repetidos fueron la cooperación, la empatía, el respeto y la tolerancia. El segundo eje más mencionado está relacionado con el crecimiento personal del estudiante que es educado en la diversidad.

El segundo análisis se orientó a los problemas educativos y las propuestas de mejora. A las personas entrevistadas se les invitó a mencionar cuáles son las principales situaciones problemáticas con las cuales se enfrentan los maestros en temas de diversidad escolar y cuáles serían sus propuestas para mejorar el trabajo en la escuela para la inclusión educativa. Los resultados arrojaron como elemento unánime para aquellos entrevistados en formación, que la relación con la familia es el principal problema:

Sé que hay algunas veces que a lo mejor los padres (...) que no están de acuerdo con ciertas metodologías (Entrevistada nivel 1).

Seguramente que sea, los padres también tengan una gran repercusión en este asunto, seguramente, sí (Entrevistado nivel 1).

También, el tema de las familias, que muchas veces ahí es la confrontación entre las familias y la escuela porque o lo padres dicen que no hay ningún problema, pues eso, que los niños son los mejores del mundo, los suyos; o que no quieren participar, que, si la maestra les da unas pautas para que sigan en casa, para que continúen con el trabajo que hay en la escuela, que no lo hagan (Entrevistada nivel 2).

No se puede condenar a una niña por una irresponsabilidad de sus padres, porque tú tienes que darlo todo por la niña, aparte de, independientemente, los padres (Entrevistado nivel 2).

Para los entrevistados que ya ejercían la docencia, la principal problemática era la necesidad de recursos, tanto humanos, como materiales o espacios físicos:

Sí, por ejemplo, un problema que te puedes encontrar es el material que puedas tú tener en el aula o la distribución de espacios (...) los especialistas, que eso es un recurso personal, pueden ser recursos materiales o recursos personales también: en no poder contar con algún especialista que a mí me ayude en el aula o de manera continua trabajar con ese niño (...) entonces eso perjudica, puede ser un problema, los recursos personales y materiales (...) mi colegio no tiene ni ascensor ni nada, o sea si un niño... no podría acceder, no es inclusivo en ese sentido, en el sentido de las instalaciones (Entrevistada nivel 3).

Entonces uno de los problemas que surge es no saber cómo actuar ante esas situaciones, por falta de recursos, de tanto la administración: sería ideal por ejemplo que hubiera más de un maestro en el aula y de esa manera atender mucho mejor a todas las características de nuestro alumnado (Entrevistado nivel $3)$.

Respecto a problemáticas de menor impacto, las y los participantes del nivel 2 y nivel 3 indicaron que aún existe la necesidad de especialización y formación continua para las y los docentes respecto al tema de la inclusión en las aulas: 
Problemas de nuestra formación, de no saber cómo afrontarlo, porque yo en la universidad no lo he visto. Yo sí lo he visto y sé cómo hacerlo, y opté por el máster por mi trabajo para, precisamente, darle a mis clases un enfoque inclusivo, pero si otro maestro ha estudiado hace años o incluso, en mi misma profesión, no se ha preocupado por quererse formar más sobre ese tema, pues imagino que cuando se encuentre con un aspecto lo tratará de la mejor manera posible, pero a lo mejor le faltan estrategias y le falta conocimiento sobre cómo trabajarlo (Entrevistado nivel 3).

Igual falta de información o falta de preparación también, porque yo creo, de acuerdo a lo que hablo con mi tutora del tema de inclusión, es que hace veinte años (digamos, las docentes que están ahora ejerciendo), no se daba en las escuelas. Y ellas, en su formación, han tenido que aprenderlo pues, es lo que no tienen (Entrevistada nivel 2).

Dentro de las acciones sugeridas para enfrentar estos problemas se encuentran las siguientes:

Tabla 5. Propuestas para generar escuelas inclusivas

\begin{tabular}{ll}
\hline Entrevistados & Propuestas \\
\hline Nivel 1 & Creación de políticas de valoración de la labor docente a nivel país. \\
& Formar en metodologías activas (eliminar la conciencia educativa \\
& tradicional). \\
& Fomentar la igualdad en la sociedad en general. \\
& Concienciación social sobre la importancia de la inclusión educativa. \\
& Dar a conocer a los maestros y maestras el currículum orientado a la \\
& diversidad. \\
& Generar propuestas de formación del profesorado permanentes en el \\
& tiempo. \\
& Invitar a los docentes a tener más experiencias educativas \\
& (intercambios, cursos, etc.). \\
& Dotar de instalaciones y recursos materiales y personales a las \\
& escuelas. \\
& Implementar metodologías activas e inclusivas: crear comunidades de \\
& aprendizaje, trabajar la cooperación, etc. \\
\hline
\end{tabular}

Los entrevistados que corresponden al nivel 1 y 2 orientaron su discurso al fortalecimiento de la labor docente y la formación continua. Por otro lado, los entrevistados de nivel 3 se enfocaron más en aspectos de implementación de metodologías y adaptación de espacios y materiales.

Para descubrir las actitudes de las y los participantes en su rol docente, se les invitó a describir qué metodologías o estrategias conocían o aplicarían para fomentar aulas inclusivas. En este ámbito, respecto a estrategias se mencionaron: el conocer a cada uno de los estudiantes en cuanto a sus necesidades y gustos, el trabajo con juegos de presentación, el trabajo dialógico, el uso de metáforas de la diferencia y el uso de tarjetas con roles. En cuanto a uso de metodologías se mencionó gran cantidad de veces la teoría de las inteligencias múltiples, el trabajo por competencias, los grupos interactivos, el planificar luego de conocer a los alumnos y fomentar la autoevaluación y coevaluación.

\section{Concepciones sobre Inclusión educativa}


Un tercer elemento por identificar en este estudio es aquel que clasifica las concepciones que poseen las y los participantes del estudio respecto a la inclusión educativa. Para alcanzar este objetivo se utilizó el modelo de López, Echeita y Martín (2010), que propone una serie de situaciones hipotéticas en la escuela y alternativas de acción.

Las concepciones, según el punto de vista del actor educativo se pueden encasillar en variadas dimensiones teóricas y estas dimensiones se pueden subdividir de manera que, según la posición de respuesta del participante del estudio, se puede establecer un perfil. En esta investigación se abordaron los siguientes perfiles:

Tabla 6. Dimensiones, subdimensiones aplicadas en la investigación

\begin{tabular}{|c|c|c|c|c|}
\hline Dimensión & Subdimensión & & Posiciones & \\
\hline & & $\begin{array}{c}\text { Teoría } 1 \\
\text { Perfil segregador }\end{array}$ & $\begin{array}{c}\text { Teoría } 2 \\
\text { Perfil integrador }\end{array}$ & $\begin{array}{c}\text { Teoría } 3 \\
\text { Perfil inclusivo }\end{array}$ \\
\hline $\begin{array}{l}\text { I. Diferencias } \\
\text { individuales }\end{array}$ & $\begin{array}{l}\text { Naturaleza de } \\
\text { las diferencias }\end{array}$ & Estática & Situacional & Interaccionista \\
\hline \multirow[t]{2}{*}{$\begin{array}{l}\text { II. Respuesta } \\
\text { educativa }\end{array}$} & $\begin{array}{l}\text { Responsabilidad } \\
\text { de los apoyos }\end{array}$ & $\begin{array}{l}\text { Especialización o } \\
\text { delegación }\end{array}$ & Complementariedad & Interdependencia \\
\hline & $\begin{array}{l}\text { Adaptación de los } \\
\text { métodos y } \\
\text { objetivos }\end{array}$ & Selectiva & $\begin{array}{l}\text { Adaptación de } \\
\text { objetivos }\end{array}$ & Adaptativa \\
\hline \multirow[t]{4}{*}{$\begin{array}{l}\text { III. Ideología y } \\
\text { valores }\end{array}$} & $\begin{array}{l}\text { Ideología } \\
\text { educativa }\end{array}$ & Liberal & Igualitaria & Pluralista \\
\hline & Nivel de equidad & $\begin{array}{l}\text { Igualdad de } \\
\text { oportunidades }\end{array}$ & $\begin{array}{l}\text { Igualdad de } \\
\text { acceso o } \\
\text { tratamiento }\end{array}$ & $\begin{array}{l}\text { Igualdad de } \\
\text { resultados }\end{array}$ \\
\hline & $\begin{array}{l}\text { Valores } \\
\text { declarados }\end{array}$ & Individualismo & Solidaridad & Justicia \\
\hline & $\begin{array}{l}\text { Actitud de mejora } \\
\text { escolar }\end{array}$ & Statu quo & Conformismo & $\begin{array}{l}\text { Optimismo o } \\
\text { innovación }\end{array}$ \\
\hline
\end{tabular}

A modo general, las personas participantes del estudio presentaron actitudes educativas concordantes con el perfil educativo inclusivo, el cual se determinó por elecciones reflexivas en situaciones hipotéticas encasilladas en la teoría 3. Lo llamativo fue que muchas veces las y los entrevistados no estaban de acuerdo con las situaciones expuestas (ejemplos éticos) lo que los llevó a generar propuestas alternativas concordantes con el perfil inclusivo.

Al analizar cada subdimensión, los resultados arrojaron que:

En las preguntas referidas a situaciones hipotéticas que identificaban concepciones sobre la naturaleza de las diferencias, en cinco de los seis casos el perfil correspondió a la postura interaccionista.

En la pregunta referida a las concepciones sobre responsabilidad de los apoyos, la totalidad de los participantes estuvieron de acuerdo con la acepción que representaba 
un punto de vista relacionado con la interdependencia de los roles dentro de una escuela.

En la pregunta referida a las concepciones sobre adaptación de los métodos y objetivos, la totalidad de los participantes indicaron estar de acuerdo con la alternativa que supone una postura adaptativa general de las actividades educativas.

En la pregunta referida a las concepciones sobre el nivel de equidad, cuatro de los participantes se identificaron con un perfil de igualdad de resultados, mientras que los casos restantes se identificaban con un perfil de igualdad de oportunidades.

En la pregunta referida a la actitud sobre la mejora escolar, la totalidad de los participantes estuvo de acuerdo con la respuesta referida a un perfil optimista o innovador.

En la pregunta referida a los valores declarados, hubo posturas discordantes, dos de los participantes se identificaron con el perfil de la justicia, tres sintieron afinidad por la solidaridad y uno indicó como preciso el concepto del individualismo.

En la pregunta referida a la ideología educativa, en tres de los seis casos existió una visión pluralista de la educación, dos casos de ideología igualitaria y un caso de ideología liberal.

\section{Discusión}

Al observar y comparar los resultados obtenidos con los estudios marco de la investigación se pueden identificar variadas diferencias que se prestan a la reflexión.

Desde un punto de vista general, existe concordancia de la investigación aquí desarrollada con los hallazgos del trabajo de Garnique (2012), quien observa un imaginario de las y los maestros centrado en el concepto de inclusión respecto a los colectivos marginados (identificados con etiquetas clave, como "gitanos", "personas autistas", "personas con necesidades educativas especiales", etc.). Este punto de vista se condice más con el modelo de integración social y equidad, más que la aceptación de la diversidad como un beneficio para todos.

En el eje de las representaciones sociales sobre inclusión de maestras y maestros, Garnique (2012) declara que en el campo de representación existe una vinculación predominante del docente inclusivo con el contexto educativo y el trabajo de aula. En el estudio desarrollado con estudiantes de Magisterio y docentes noveles la caracterización se fundamentó principalmente en el campo axiológico, o sea en aquellas reflexiones relacionadas con los valores educativos en los entrevistados que poseían experiencia en aula, seguido del campo social en aquellos entrevistados que poseían poca o nula experiencia en aula. Raramente las imágenes de inclusión se situaron dentro del trabajo de aula en aquellos entrevistados que ejercían la profesión. En este aspecto es bueno aclarar que el trabajo de Garnique (2012) se realizó en un contexto distinto, con maestros y maestras con años ejerciendo la labor docente, por ello, el aula correspondía a una referencia fundamental.

Otro aspecto que destaca Garnique en su estudio es la visualización mayoritaria de la inclusión dentro del aula como proceso político e identitario. Los entrevistados del 
estudio aquí descrito rara vez manifiestan concepciones políticas o identificación de la importancia de la acción política para lograr los objetivos de la educación inclusiva.

En la dimensión que caracteriza la problemática de la inclusión desde un ámbito económico, Garnique declara en su estudio un discurso de denuncia hacia la escasez de recursos económicos (falta de capacitación, falta de materiales, falta de recursos). En esta línea, los participantes en nuestro trabajo observan la problemática desde un enfoque especialmente social, en donde las barreras para la inclusión educativa se encuentran en la relación entre las escuelas con las familias. Llama la atención este hallazgo, pues, para las y los participantes, la relación docente-familia resulta determinante para definir las estrategias que se planifican. Reparaz y Naval (2014), desarrollan un estudio sobre la carga que representa para los docentes el proponer a las familias propuestas pedagógicas distintas a lo tradicional, hecho que, al parecer, se replica en el contexto español general (Bonell y Ríos, 2014).

En la línea que identifica las formas y modos con los cuales los docentes se informan sobre inclusión educativa, Garnique (2012) declara que en su investigación resultó imposible identificar fuentes de información diferentes a la experiencia en aula. Respecto a este eje, la investigación aquí expuesta presenta cambios, pues todos los entrevistados recordaron al menos una experiencia formativa en la cual habían obtenido información y/o herramientas sobre inclusión educativa. Sin embargo, es bueno señalar que gran parte de los procesos formativos habían sido obligatorios para su formación profesional (asignaturas del plan de estudios de Grado en Educación).

En la dimensión de las demandas docentes por el acceso a más información (o formación), al igual que en el estudio realizado por Garnique, preponderan las peticiones en temas orientados a la formación metodológica (acceso a información sobre la práctica docente desde la perspectiva inclusiva). Particularmente, en el caso de los entrevistados del nivel 2 y el nivel 3, la necesidad se manifiesta exponencialmente, probablemente porque los participantes del estudio ya poseen experiencia tangible en aula, por lo que se sienten capaces de requerir apoyo para trabajar con estudiantes de colectivos marginados.

En la dimensión de las actitudes de los docentes en el aula, en el estudio de Garnique (2012), la relación es ambivalente, por un lado, está el deber y por otro la culpa. Respecto a esto Garnique señala que muchos docentes se identificaban con las imágenes de inclusión educativa y se señalaban inclusivos, mas, aun así, fomentaban el trabajo individual, estereotipaban y presentaban falta de adaptación de su estilo de enseñanza al estilo de aprendizaje de sus alumnos. En nuestro estudio, existe por parte de los participantes una clara predisposición a la inclusión y conocimientos variados sobre metodologías para el desarrollo de aulas inclusivas, pero en el discurso reflexivo, se hace recurrente el uso de etiquetas sobre aquellos estudiantes que pueden presentar un desafío. Solamente cuando las y los entrevistados generaban campos de significación sobre la diversidad, apelaban a conceptos más axiológicos y generales. En esta línea, Infante (2010) expone que esta descoordinación entre la teórica y la práctica de la inclusión radica en el currículum, la organización de la escuela y la formación docente inicial, ya que muchas veces la formación docente y las instituciones encargadas de esta recaen una y otra vez en el círculo vicioso de la tradición educativa. En cuanto a la dimensión relacionada con las concepciones docentes sobre inclusión educativa, se puede mencionar como marco de referencia el trabajo de López, Echeita y Martín (2010), que, si bien presenta características muy distintas a las propuestas realizadas en el estudio aquí expuesto, utiliza el mismo entramado teórico.

Sobre la distribución de maestros, maestras y estudiantes de Magisterio y su perfil pedagógico, el estudio de referencia indicó que una proporción significativamente mayor de docentes en ejercicio elige opciones segregadoras a diferencia de las y los estudiantes de Magisterio, que representan un perfil concordante con el enfoque inclusivo. 
Para explicar por qué las maestras y los maestros conciben un punto de vista más segregador, a pesar de ser formados en metodologías colaborativas, los autores justifican que la experiencia en el aula con alumnos reales en institutos de ciertas características parece contribuir a disminuir las posiciones orientadas al constructivismo (Martín, Martín-Mateos, Echeverría y Pozo, 2008).

En cuanto a las dimensiones que conforman cada perfil, en el estudio de referencia se identificó que:

1. Las diferencias individuales eran observadas por profesoras y profesores en ejercicio desde una naturaleza estática que defiende la necesidad de la atención educativa en aulas separadas para los alumnos con dificultades.

2. La respuesta educativa, en el ámbito de la responsabilidad de los apoyos estaba orientada a la especialización o delegación, lo que indica la atención individualizada de estudiantes por profesionales especializados en dificultades específicas.

3. En el eje de adaptación de los objetivos, la concepción más aceptada era la selectiva, ya que era fundamental el trabajo en grupos homogéneos.

4. Las ideologías y valores eran consecuentes con la perspectiva de igualdad de acceso, esto debido a las bajas expectativas en el estudiantado. La ideología educativa reinante era la liberal y el valor más importante era el esfuerzo.

5. Las actitudes estaban enfocadas hacia el statu quo y el conformismo.

Las diferencias entonces, entre el estudio de López, Echeita y Martín y el aquí expuesto son notorias, ya que, en líneas generales, los entrevistados de todos los niveles poseyeron en su mayoría, concepciones sobre naturaleza de las diferencias en el eje interaccionista; concepciones sobre la responsabilidad de los apoyos desde la interdependencia; adaptación de los métodos y objetivos hacia el grupo; una ideología predominantemente igualitaria y pluralista; un nivel de equidad basado en la igualdad de resultados y oportunidades; valores declarados hacia la solidaridad y la justicia, y finalmente, una actitud optimista generalizada.

\section{Referencias}

Ainscow, M. (2001). Hacia escuelas eficaces para todos. Manual para la formación de equipos. Madrid: Narcea.

Ainscow, M. (2005). Para comprender el desarrollo del Sistema Educativo Inclusivo. Electronic Journal of Research in Educational Psychology 3 (3), 5-20.

Ainscow, M., Beresford, J., Harris, A., Hopkins, D. \& West, M. (2001). Crear condiciones para la mejora del trabajo en el aula. Manual para la formación del profesorado. Madrid: Narcea.

Alonso, L. (1994). Métodos y técnicas cualitativas de investigación en Ciencias Sociales. Madrid: Síntesis.

Arnaiz, P. (2003). Educación Inclusiva: Una escuela para todos. Málaga: Editorial Aljibe.

Bonell, L., \& Ríos, O. (2014). Participation and family education in school: Successful educational actions. Studies in the Education of Adults, 46 (2), 177-191.

Cardona, M. C. (2006): Diversidad y educación inclusiva: enfoques metodológicos y estrategias para una enseñanza colaborativa, Madrid: Editorial Alhambra.
Coll, C. y Miras, M. (2001). Diferencias individuales y atención a la diversidad en el aprendizaje escolar. Madrid: Alianza Editorial.

Echeita, G. (2006). Educación para la inclusión o educación sin exclusiones. Madrid: Narcea.

Escudero, J. \& Martínez, B. (2006). Educación inclusiva y cambio escolar. Revista Iberoamericana de Educación. 55, 85-105.

Etxebarría, X. (2003). Ética de la relación con las personas con discapacidad intelectual. En M.A. Verdugo y F.B Jordan de Urries de Vega (coord.) Investigación, innovación y cambio, pp.353-366. Salamanca: Amaru.

Garnique, C. (2012). Las representaciones sociales: Los docentes de educación básica frente a la inclusión escolar. Perfiles educativos, 34 (137), 99-118.

Granada, M., Pomés, M. P., \& Sanhueza, S. (2013) Actitud de los profesores hacia la inclusión educativa. Papeles de trabajo, 25, $51-59$

Infante, M. (2010). Desafíos a la formación docente: inclusión educativa. Estudios pedagógicos, 36 (1), 287-297. 
Klinger, C., C. Mejía y L. Posada (2011). La inclusión educativa: un escenario de expresiones afectivas como mediadoras del aprendizaje, Plumilla Educativa, 8 (12), 1657-4672

López, V. (1999). Educación Física, evaluación y reforma. Segovia: Diagonal.

López, M., Echeita, G., \& Martín, E. (2010). Dilemas en los procesos de inclusión: explorando instrumentos para una comprensión de las concepciones educativas del profesorado. Revista latinoamericana de educación inclusiva, 4 (2), 155-176.

Martín, E.; Pozo, J.; Mateos, M.; Martin, A. \& Echeverría, M. (2014). Concepciones de enseñanza y aprendizaje de profesores de infantil, primaria y secundaria y la relación con las variables educativas. Revista Latinoamericana de Psicología, 46 (1-3), 211-222.

Marchesi, A. y Martín, E. (1998). Calidad de la enseñanza en tiempos de cambio. Madrid: Alianza.

Moscovici, S. (1987). Psicología Social, Pensamiento y vida social. Cognición y desarrollo humano. Barcelona: Paidós.
Reparaz, C., \& Naval, C. (2014). Bases conceptuales de la participación de las familias. Madrid: Narcea.

Sánchez, A., Díaz, C., Sanhueza, S., \& Friz, M. (2008). Percepciones y Actitudes de Los Estudiantes De Pedagogía hacia la Inclusión Educativa. Estudios pedagógicos, 34 (2), 169-178.

Stenhouse, L. (1984). Investigación y desarrollo del currículo. Madrid: Morata.

UNESCO (1990). Final Report: World Conference on Education for All - Meeting Basic Human Needs. París: UNESCO.

Vallés, M. (2000.) Técnicas cualitativas en investigación. Reflexión metodológica y práctica profesional. Madrid: Síntesis Sociología.

Wengraf, T. (2001). Qualitative research interviewing: Biographic narrative and semi-structured methods. Nueva York: Sage.

\section{Anexos}

Guion de entrevista

Preguntas adaptadas del trabajo de Garnique (2012) Para docentes en ejercicio:

- ¿ ¿Por qué se dice que la educación debe ser inclusiva?

- ¿Qué problemas estudia y busca resolver la inclusión educativa?

- ¿ ¿Cuándo escucha la palabra "inclusión" ¿Qué aspectos de su vida diaria dentro y fuera de la escuela le vienen a la mente?

- ¿Considera que en los grupos en los cuales trabaja hay características de diversidad? ¿Por qué?

- ¿Qué valores y relaciones se fomentan en los niños cuando se trabaja con la Inclusión de la Diversidad? Estos valores ¿se practican en la vida diaria en su escuela?

- ¿Cómo se considera la inclusión de la Diversidad escolar en los contenidos del Plan de Estudios?

- ¿ ¿Cuál ha sido su proceso de formación en temas de Inclusión de la Diversidad? 
- Mencione 5 fines de la inclusión educativa

- Mencione seis o más palabras, problemas o temáticas para identificar la inclusión

- ¿Qué estrategias y recursos le ayudan en el proceso E-A para responder a una mayor diversidad de necesidades estudiantiles?

- ¿Cómo fomenta o propicia la inclusión en sus alumnos en la escuela?

- ¿ ¿Qué materiales emplea para la elaboración de su planificación para la atención de la diversidad estudiantil?

- ¿Cuáles son las situaciones a las que se enfrentan los profesores para trabajar con la Inclusión de la Diversidad?

- Trabaja con la Inclusión de la Diversidad por iniciativa propia o fue una imposición de la directiva de su institución.

- ¿ ¿Cómo evalúa, en su escuela, la inclusión de la diversidad escolar?

- ¿Qué características posee un educador inclusivo según su opinión? ¿Por qué?

- ¿Qué propone para que se logren los fines de la Inclusión de la Diversidad en la escuela?

Preguntas adaptadas del trabajo de Garnique (2012) Para docentes en formación:

- ¿Por qué se dice que la educación debe ser inclusiva?

- ¿Qué problemas estudia y busca resolver la inclusión educativa?

- ¿ ¿Cuándo escucha la palabra "inclusión" ¿Qué aspectos de su vida diaria dentro y fuera de la escuela le vienen a la mente?

- ¿Qué valores y relaciones se fomentan en los niños cuando se trabaja con la Inclusión de la Diversidad? Estos valores ¿cómo se practicarían en la escuela según su opinión?

- ¿ ¿Conoce el Plan de Estudios del área en la cual se desempeñará como docente? (si contesta sí) ¿Cómo se considera la inclusión de la Diversidad escolar en los contenidos del Plan de Estudios?

- ¿ ¿Cuál ha sido su proceso de formación en temas de Inclusión de la Diversidad?

- Mencione 5 fines de la inclusión educativa.

- Mencione seis o más palabras, problemas o temáticas para identificar la inclusión

- $\quad$ Según su experiencia y conocimientos ¿Qué estrategias y recursos le ayudarían en el proceso E-A para responder a una mayor diversidad de necesidades estudiantiles?

- ¿Conoce las situaciones a las que se enfrentan los profesores para trabajar con la Inclusión de la Diversidad en las escuelas?

- ¿Qué características posee un educador inclusivo según su opinión? ¿Por qué?

- ¿Qué propone para que se logren los fines de la Inclusión de la Diversidad en la escuela?

Situaciones extraídas del cuestionario de López, Echeita y Martín (2010) sobre concepciones educativas:

1. Un grupo de profesores de una escuela está discutiendo cómo ayudar a un alumno que presenta retrasos importantes en casi todas las asignaturas. La discusión se ha centrado en el tiempo y esfuerzo que supone ayudar a este tipo de alumnos y los pocos avances que se han logrado. Se han manifestado 3 posiciones en la discusión:

a. Las características de estos alumnos limitan su capacidad de aprender. A veces dudamos si empeñarse en que sigan estudiando sea bueno para ellos y si quizás sea mejor que se incorporen ya al mundo laboral.

b. Estos alumnos necesitan más tiempo para aprender ya que su ritmo es más lento, por eso, deberían repetir curso y así lograr avanzar un poco más.

c. Los docentes deben identificar cuál es el tipo de apoyo que necesita este alumno y hacer un esfuerzo específico por él, aunque acabe la etapa sin aprender todos los contenidos.

2. En una reunión de profesores se discute el caso de un alumno con discapacidad intelectual que, habiendo recibido bastante apoyo por parte de sus profesores, no ha logrado resultados valiosos, según éstos. Además, algunos profesores se quejan de que los esfuerzos de colaboración con el profesor de apoyo han sido infructuosos. Para explicar lo sucedido, se exponen algunas teorías:

a. Lo que ocurre es que se ha confiado demasiado en unas capacidades del alumno que son muy limitadas. En primaria, estos alumnos pueden lograr avances, pero en secundaria es utópico planteárselo.

b. Lo que ha sucedido es que no se ha recibido el apoyo de la familia en cuanto a las actividades de estimulación que se les ha solicitado que realicen en casa.

c. Lo que ha sucedido es que, a pesar de haber hecho ajustes en la programación, no se ha contado con el profesorado de apoyo adecuado.

3. En el marco de una reunión de tutores de un instituto que integra alumnos con discapacidad intelectual se ha originado una discusión entre un profesor tutor, un profesor de apoyo y el orientador, que ha puesto de manifiesto las diferentes visiones que existen sobre las responsabilidades de unos y otros profesionales en el trabajo con este alumnado:

a. Cada profesor es especialista en su disciplina y está preparado para la enseñanza de ésta. De ahí, la importancia del profesor de apoyo, quien tiene la preparación requerida para diseñar las actividades del alumnado especial y encargarse del seguimiento de su aprendizaje.

b. Para ser eficientes lo mejor sería que el profesor de apoyo se coordinara con el tutor sobre todo para cuestiones que tienen que ver con la integración social y el desarrollo de la autonomía de estos alumnos.

c. La planificación y evaluación de las actividades en el aula de referencia debe ser una responsabilidad compartida para que se puedan beneficiar todos los alumnos, aunque esto suponga un esfuerzo de coordinación adicional por parte del profesorado.

4. Frente a la decisión del centro de incorporar alumnos con discapacidad intelectual el próximo curso, se convoca al claustro para debatir las futuras actuaciones del centro frente a estos alumnos. Las opiniones que con mayor frecuencia suscita el debate son las siguientes:

a. No está claro quién se beneficia con esta medida, ya que los profesores no pueden atender bien a estos alumnos al mismo tiempo que al resto. b. El ideal es que todos puedan estar en el aula, pero es necesario apoyar a estos alumnos en grupos especiales durante parte de la jornada, para no interferir con la programación que tiene el profesor con todo el grupo.

c. Es necesario adaptar los niveles de exigencia, los métodos y los contenidos, trabajando de forma más individualizada con todo el grupo. Una opción es desarrollar proyectos de trabajo más interdisciplinarios, aunque esto suponga un esfuerzo mayor de nuestra parte.

5. En una discusión sobre los efectos de mantener a todos los alumnos estudiando lo mismo hasta el final de la ESO, un grupo de profesores de secundaria intentan llegar a un acuerdo sobre el valor de esta forma de organización de la enseñanza, la que ha resultado muy polémica: a. Estamos todos de acuerdo en que la igualdad es poner la educación al alcance de todos, pero eso significa que debemos permitir que cada alumno oriente su futuro hacia donde pueda realmente, sin crear en él falsas expectativas.

b. La escuela comprensiva es importante para asegurar a todos la misma educación, pero al tener grupos cada vez más heterogéneos en el aula, muchas veces nos vemos obligados a rebajar los niveles de exigencia.

c. La verdadera igualdad significa que las metas educativas en la enseñanza obligatoria sean las mismas para todos, que todos adquieran las competencias básicas como ciudadanos. Pero el problema es que este ideal se hace cada día más difícil en la realidad. 
6. El claustro de un instituto se ha reunido para evaluar su experiencia con la inclusión educativa. Ésta ha sido definida como el proceso de promover el acceso, la participación y el aprendizaje, en condiciones de igualdad de todos los alumnos en el centro escolar. Al respecto, existen visiones claramente discrepantes:

a. La inclusión es una idea de los estudiosos de la universidad que está lejos de la realidad del aula. Ello implica que los docentes tenemos que asumir problemas que antes no teníamos.

b. La inclusión es un proyecto de buenas intenciones, pero en la práctica no se cuenta con los recursos ni con la especialización necesaria para atender a los alumnos con mayores dificultades.

c. La inclusión ofrece una buena oportunidad para contrastar los valores positivos que las leyes educativas establecen con las prácticas que finalmente se implementan en los centros, pero muchas veces las condiciones no permiten hacer efectivos estos valores.

7. Un instituto está organizando la Semana de los Valores. Durante ésta se espera que profesores, padres y alumnos participen en actividades que promuevan los valores que la comunidad educativa considera más importantes. Sin embargo, ha sido enormemente difícil ponerse de acuerdo en cuáles son estos valores, manifestándose tres visiones mayoritarias:

a. Un valor que debemos fomentar es la cultura del esfuerzo, que los jóvenes de hoy parecen haber perdido. Los alumnos que salen adelante y triunfan son aquellos que se esfuerzan por superar todos los obstáculos que la vida les plantea.

b. Un valor que debemos fomentar es la solidaridad, ya que es importante que aquellos alumnos más favorecidos ayuden a sus compañeros con más dificultades y a aquellos que están en situaciones de mayor vulnerabilidad.

c. Un valor que debemos fomentar es la justicia, ya que si la escolarización redistribuye las oportunidades educativas -ofreciendo más ventajas a los que están en desventaja- ésta contribuirá a crear una sociedad más cohesionada.

8. Un grupo de profesores está discutiendo si la libertad de los padres a elegir el centro de sus hijos es un valor educativo esencial o si tiene que hacerse compatible con un reparto equilibrado del alumnado entre los centros públicos y concertados. Se expresaron tres opiniones:

a. Los padres son los principales responsables en la educación de sus hijos, por lo que deben tener la libertad para escoger la escuela en la que éstos se educan, aunque ello suponga que aumenten las diferencias entre los centros.

b. Los centros públicos y concertados deberían escolarizar un determinado porcentaje de alumnos con discapacidad y de origen inmigrante, aunque ello suponga que no todos los alumnos puedan escolarizarse donde sus padres quieren.

c. La educación es un bien social y el Estado debe asegurar la eficacia de todos los centros públicos, de manera que no se obligue a los padres a tener que elegir un centro distinto al de su barrio. 